\title{
Effective Timing of Surgical Resection of Colorectal Cancer Liver Metastases During Chemotherapy
}

\author{
SHINJI OSADA ${ }^{1}$, AYANA GOTOH ${ }^{2}$, RYOMA YOKOI ${ }^{2}$, HIROSHI TSUCHIYA ${ }^{2}$, TAKUJI SAKURATANI ${ }^{2}$, \\ YOSHIYUKI SASAKI ${ }^{1}$, NAOKI OKUMURA ${ }^{2}$, HIDEKI HAYASHI ${ }^{1}$ and TSUYOSHI MUKAI ${ }^{1}$ \\ ${ }^{1}$ Hepato-Biliary Pancreas Center, ${ }^{2}$ Department of Surgery, Gifu Municipal Hospital, Gifu, Japan
}

\begin{abstract}
Background/Aim: The aim of the present study was to further develop our previous study on c-Met expression in colorectal cancer and epithelial-mesenchymal transition (EMT) induced by hepatocyte growth factor (HGF), to investigate EMT in the process of liver metastases, and evaluate the effects of chemotherapy on EMT cells as a therapeutic strategy for colorectal liver metastasis. Materials and Methods: CT26 colon cancer cells were treated with 5-FU and oxaliplatin with or without HGF. The signaling pathway was evaluated by western blotting analysis, and drug resistance was evaluated by the MTT (3-(4,5-dimethyl2-tetrazolyl)-2,5-diphenyl-2H tetrazolium bromide) assay. Results: Under pretreatment with HGF for $96 h, 5 \mu M$ and $10 \mu M$ of 5-FU mediated significant growth inhibition by $72.5 \pm 3.9 \%$ and $76.2 \pm 2.4 \%$, respectively, compared to $H G F$ alone, and by $105.1 \pm 2.8 \%$ and $103.5 \pm 2.9 \%$, respectively, without HGF. The expression of E2F1 was decreased significantly to $50.5 \pm 3.8 \%$ after 24 hours by $H G F$ with a reduction of both cyclin DI to $52.1 \pm 7.0 \%$ and $E$ to $73.7 \pm 3.8 \%$. Thymidylate synthase was also decreased in a time-dependent manner to $80.6 \pm 2.0 \%$ after $24 \mathrm{~h}$ and to $52.7 \pm 1.5 \%$ after $96 \mathrm{~h}$. Conclusion: The presence of HGF was found to increase the 5-FU-induced death signal, JNK pathway, and inhibition of cell growth. As its mechanism, $H G F$ was shown to decrease E2F-1 by reducing cyclin D or $E$ by cell-cycle activation, resulting in inactivation of thymidylate synthase. The chemotherapeutic effect of 5-FU was increased in HGF- but not TGF- $\beta$-induced EMT.
\end{abstract}

Colorectal cancer (CRC) is the third most common epithelial malignancy worldwide (1). Liver metastases developed from CRC represent one of the most frequent

Correspondence to: Shinji Osada, Hepato-Biliary-Pancreas Center, Gifu Municipal Hospital, 7-1, Kashimacho, Gifu 500-8513, Japan. Tel: +81 582511101, Fax: +81 582511335, e-mail: sting_7237@yahoo.co.jp

Key Words: Colorectal Cancer, liver metastases, hepatocyte growth factor (HGF), c-Met, epithelial-mesenchymal transition (EMT). causes of death, affecting approximately $70 \%$ of patients (2). Improved combinations of 5-fluorouracil (5-FU)/folinic acid with irinotecan (FOLFIRI) or oxaliplatin (FOLFOX) have progressively increased tumor response to $73 \%$, and the median survival time has risen to 20 months (3). Surgical resection has also remained an expected procedure to ensure long-term survival or cure (4). More favorable survival rates are obtained with preoperative chemotherapy compared to surgery alone (5), and combination of these treatments achieves 5-year survival rates of up to $60 \%$ (6). However, in the process of liver regeneration after hepatectomy, the relation between the activation of the hepatocyte growth factor (HGF)-induced its receptor, cMet, signaling pathway and cancer progression remains unknown (7).

Epithelial-mesenchymal transition (EMT) is a process by which differentiated epithelial cells transition to a mesenchymal phenotype. EMT enables the escape of epithelial cells from the rigid structural constraints of the tissue architecture to a phenotype more amenable to cell migration, thus, creating invasion and metastasis (8). Among various soluble factors to correlate with EMT, HGF is related to poor prognosis of patients with small cell lung cancer through a high rate of metastasis to several organs (9) and directly promotes carcinogenesis of hepatocellular carcinoma (10). On the other hand, the early response to anticancer agents in the progress of EMT is still unclear and controversial. Some reports showed EMT to relate to higher chemosensitivity (11), whereas its expression has also been related to lower chemosensitivity (12). To clarify this, we showed that pretreatment of CRC cells with HGF enhanced 5 -FU-induced cell death by $63 \%$ compared with the control during the expression of signaling pathway by HGF/c-Met activation (1); however, its mechanism remains unclear. The purpose of the present study was to further develop our previous study on c-Met expression in CRC and EMT induced by HGF, to investigate EMT in the process of liver metastases, and to evaluate the effects of chemotherapy on EMT cells as a therapeutic strategy for colorectal liver metastasis. 


\section{Materials and Methods}

Cell lines and culture conditions. Cells from the CT26 murine colorectal carcinoma cell line were obtained from the American Type Culture Collection (ATCC, Manassas, VA, USA). Cells were cultured in RPMI-1640 medium (Wako, Osaka, Japan) supplemented with $10 \%$ heat-inactivated fetal bovine serum (FBS), $1 \mathrm{mM}$ HEPES buffer, $1 \mathrm{mM}$ sodium pyruvate solution, and $1 \%$ penicillin-streptomycin-amphotericin solution (all from SigmaAldrich, St. Louis, MO, USA) in a humidified atmosphere of $5 \%$ $\mathrm{CO}_{2} / 95 \%$ air at $37^{\circ} \mathrm{C}$. Cells were passaged twice a week.

Cell proliferation assay. Cell growth was assessed by a standard 3(4,5-dimethyl-thiazol-2-yl)-2,5- diphenyltetrazolium bromide (MTT) assay $(1,7)$, which detects the dehydrogenase activity in viable cells. A total of $5 \times 10^{3}$ CT26 cells were seeded into each of the 96well culture plates or the same density of cells was seeded into 6well culture plates overnight and kept in a humidified atmosphere of $5 \% \mathrm{CO}_{2}$ and $95 \%$ air at $37^{\circ} \mathrm{C}$. The medium was exchanged for serum-free RPMI-1640 medium, and after 48-h incubation, growth stimulation by growth factors was started by adding $5 \mathrm{ng} / \mathrm{ml}$ of transforming growth factor- $\beta$ (TGF $\beta$ ) and $20 \mathrm{ng} / \mathrm{ml}$ of HGF to each well in the same condition. Recombinant TGF- $\beta 1$ and recombinant HGF were purchased from R\&D Systems (Minneapolis, MN, USA). After $0,24,48,72$ or $96 \mathrm{~h}, 0,5$ or $10 \mu \mathrm{M}$ of 5 -FU was added to the culture medium. After 48-h incubation, $100 \mu \mathrm{l}$ of a $0.5 \mathrm{mg} / \mathrm{ml}$ solution of MTT (Sigma-Aldrich, Darmstadt, Germany) was added to each well. The plates were then incubated for $4 \mathrm{~h}$ at $37^{\circ} \mathrm{C}$. The culture medium was replaced with $100 \mu \mathrm{l}$ of dimethyl sulfoxide (Wako, Osaka, Japan) per well, and the absorbance at the 540-nm wavelength was measured using a 2104 EnVision Multilabel Reader (Perkin-Elmer, Waltham, MA, USA).

Western blot analysis and antibodies. Treatment of the specimens was as described previously $(1,7)$. Cell lysates were boiled in Sample Buffer Solution (Wako, Osaka, Japan). Total cell protein extracts (20 or $40 \mu \mathrm{g} /$ lane) were separated by sodium dodecyl sulfate-polyacrylamide gel electrophoresis using SuperSep ${ }^{\mathrm{TM}}$ (Wako, Osaka, Japan) and were electrophoretically transfected onto polyvinyl difluoride membranes. The membranes were blocked with PVDF blocking reagent (Toyobo, Osaka, Japan) for $1 \mathrm{~h}$. The membranes were then incubated overnight at $4^{\circ} \mathrm{C}$ with primary antibodies against Notch1 (D1E11) XP rabbit mAb (Cell Signaling Technology, Denver, MA, USA), $\beta$-catenin rabbit mAb (Cell Signaling Technology, Denver, MA, USA), ZEB1 antibody (NOVUS Biologicals, Littleton, CO, USA), phospho-c-Jun N-terminal kinase (JNK) mouse mAb (Cell Signaling Technology, Denver, MA, USA), phospho p44/42 MAP kinase (Erk1/2) antibody (Cell Signaling Technology, Denver, MA, USA), cleaved PARP (Asp214) antibody (Cell Signaling Technology, Denver, MA, USA), caspase-3 antibody, cyclinB1 antibody (Cell Signaling Technology, Denver, MA, USA), cyclinD1 rabbit mAb (Cell Signaling Technology, Denver, MA, USA), cyclinE mouse mAb, anti-E2F1 antibody (ab96864) (Abcam, Cambridge, UK), thymidine synthase antibody (kindly provided TAIHO, Tokyo, Japan), and phospho-NF-kBp65 (Ser468) antibody (Cell Signaling Technology, Denver, MA, USA). The primary antibodies were diluted with Can Get Signal Solution 1 (Toyobo, Osaka, Japan). The membranes were then washed with Dako Washing Buffer (Dako, Glostrup, Denmark) and incubated with the appropriate secondary antibodies (1:25.000; Millipore, Darmstadt,
Germany), which were diluted with Can Get Signal Solution 2 (Toyobo, Osaka, Japan). The immunoreactive proteins were visualized by chemiluminescence using ImmunoStar LD reagents (Wako, Osaka, Japan), and images were captured by a GeneGnome Bio Imaging System (Syngene, Cambridge, UK). The detected band was analyzed by ImageJ computer software, as described previously. Each value was obtained from the comparison with the level of rabbit polyclonal anti $\beta$-actin (Abcam, Tokyo, Japan), and the mean values were calculated from three repeated measures (13).

Statistical analysis. The data were examined using the Student $t$-test, Chi-square test, and ANOVA or Kruskal-Wallis test (with appropriate post hoc analysis for multiple comparisons) to determine statistical significances. $p$-Values of less than 0.05 were regarded as statistically significant.

\section{Results}

Mediated signal pathway. In the CT26 mouse CRC cells, the $\mathrm{IC}_{50}$ by 5 -FU at $48 \mathrm{~h}$ was determined to be $24.0 \pm 2.0 \mathrm{mM} .5-$ FU-induced cell signaling pathways for the CT26 cell line were evaluated (Figure 1). Compared with the bands detected by Western blotting in the control, 5-FU increased activated JNK to $226.4 \pm 34.4 \%$ and reduced ERK phosphorylation to $48.1 \pm 1.8 \%$ after $30 \mathrm{~min}$, and increased cleaved-type PARP to $569.9 \pm 2.0 \%$ and caspase -3 to $154.7 \pm 1.1 \%$, as an apoptosis pathway, after $12 \mathrm{~h}$. 5-FU also decreased the amount of cyclin B1 to $68.4 \pm 4.0 \%$ and increased cyclin D1 to $153.9 \pm 9.0 \%$ after $24 \mathrm{~h}$. The effect of oxaliplatin as another common chemotherapeutic agent for CRC on cell growth and the signaling pathway was examined (Figure 2). The $\mathrm{IC}_{50}$ of oxaliplatin was $84.0 \pm 12.2 \mu \mathrm{M}$, and it increased the activated type of both JNK and ERK to $106.2 \pm 0.8 \%$ and $132.2 \pm 40.7 \%$, respectively, after $30 \mathrm{~min}$, and the apoptosis pathway cleaved PARP to $836.9 \pm 115.9 \%$ and caspase -3 to $742.5 \pm 148.1 \%$ after $12 \mathrm{~h}$ in a dose-dependent manner. Oxaliplatin was also found to decrease both cyclin B1 and D1 to $16.1 \pm 0.8 \%$ and $14.5 \pm 1.3 \%$ after $24 \mathrm{~h}$, respectively.

The signaling pathway related to EMT was also studied (Figure 3). Both TGF $\beta$ as the most common inducer for EMT and HGF decreased the expression of E-cadherin to $39.0 \pm 0.2 \%$ and $51.1 \pm 1.0 \%$ for $72 \mathrm{~h}$ or more. TGF- $\beta$ induced the activation of ZEB1 to $151.3 \pm 9.1 \%$ after $24 \mathrm{~h}$ and Notch 1 to $51.5 \pm 3.4 \%$ after $48 \mathrm{~h}$ and decreased the expression of $\beta$-catenin in a timedependent manner. The activation of these pathways was not detected by HGF, and as a factor of anti-cancer drug resistance, $\mathrm{NFkB}$ was not activated by either TGF- $\beta$ or HGF.

The effect of 5-FU on the action of HGF to induce EMT was studied (Figure 4). Under pretreatment with HGF for $96 \mathrm{~h}, 5 \mu \mathrm{M}$ and $10 \mu \mathrm{M} 5-\mathrm{FU}$ mediated significant growth inhibition by $72.5 \pm 3.9 \%$ and $76.2 \pm 2.4 \%$, respectively, compared with HGF alone, and by $105.1 \pm 2.8 \%$ and $103.5 \pm 2.9 \%$, respectively, without HGF. From observations of the signaling pathway, 5-FU-induced JNK activation was significantly increased by pretreatment with HGF, but not 
A

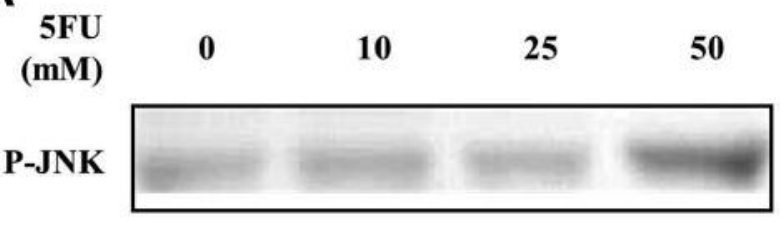

P-ERK

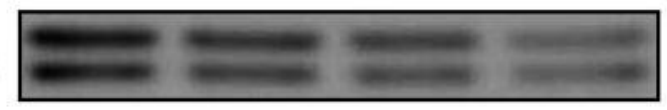

$\beta$-actin

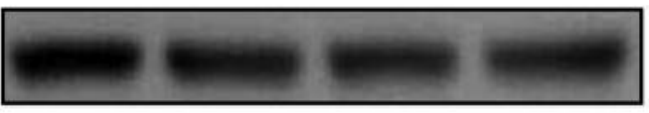

B

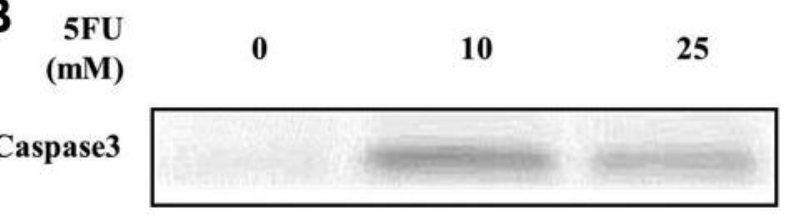

\section{Cleaved}

PARP

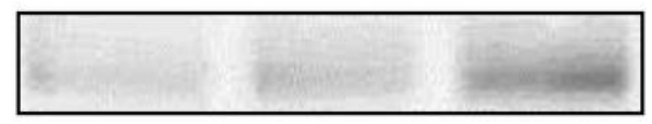

$\beta$-actin

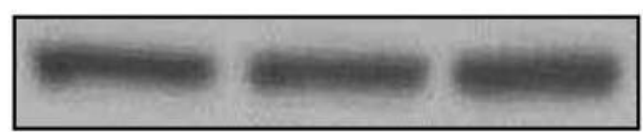

C 5 FU

(mM)

0

10

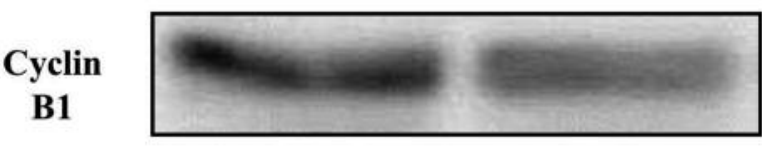

\section{Cyclin} D1

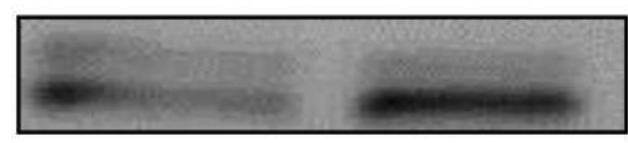

\section{$\beta$-actin}

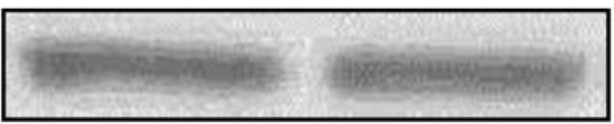

Figure 1. 5-FU-induced cell signaling pathway. 5-FU mediated the activation of JNK and reduced phosphorylation of ERK after 30 minutes (A). The cleaved band of PARP or caspase-3 was detected by incubation with $25 \mathrm{mM}$ or $10 \mathrm{mM}$ of $5-F U$, respectively, for $12 \mathrm{~h}(\mathrm{~B})$. Cyclin B1 was decreased and cyclin D1 was increased by incubation with $10 \mathrm{mM}$ of 5-FU for $24 \mathrm{~h}(\mathrm{C})$. Cell death was high when $25 \mathrm{mM}$ of 5-FU was used, and an inadequate amount of protein was obtained.
A

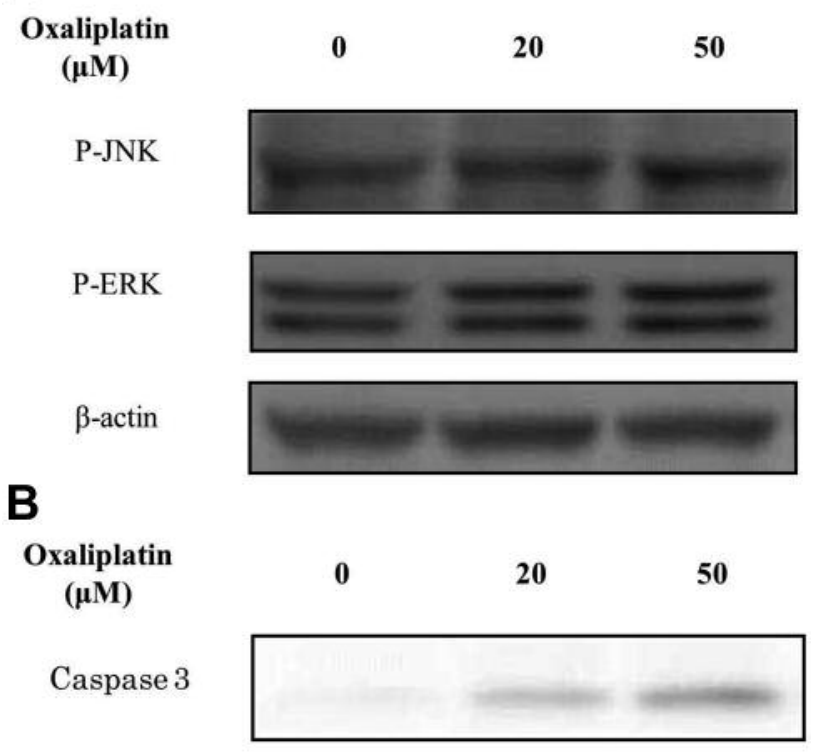

Cleaved

PARP

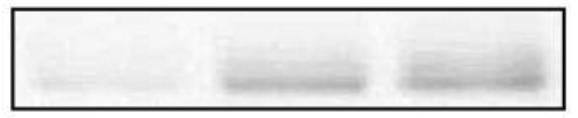

B-actin

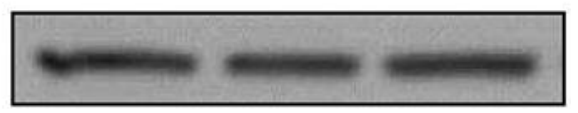

C

Oxaliplatin

0

20

50

Cyclin B1

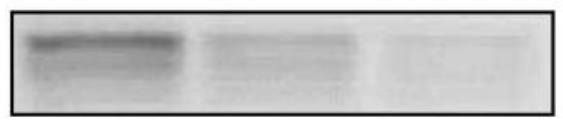

Cyclin D1

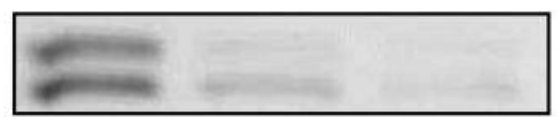

$\beta$-actin

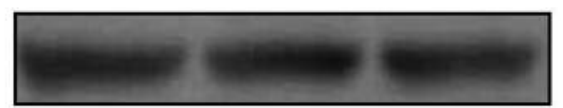

Figure 2. Oxaliplatin-mediated cell signaling pathway. Oxaliplatin mediated the activation of JNK, but not ERK, after $30 \mathrm{~min}$ (A). The cleaved band of PARP or caspase-3 was detected by incubation with $>25 \mathrm{mM}$ of oxaliplatin for $12 \mathrm{~h}$ in a dose-dependent manner $(B)$. Both cyclin B1 and Dl were decreased by incubation with $25 \mathrm{mM}$ of oxaliplatin for $24 h(C)$.

with TGF- $\beta$, for 72 or $96 \mathrm{~h}$, but not by simultaneous applications. These signaling actions were not shown by oxaliplatin (data not shown).

To estimate the mechanism of the HGF-mediated increase in the effect of 5-FU, a study of its metabolic enzymes was 


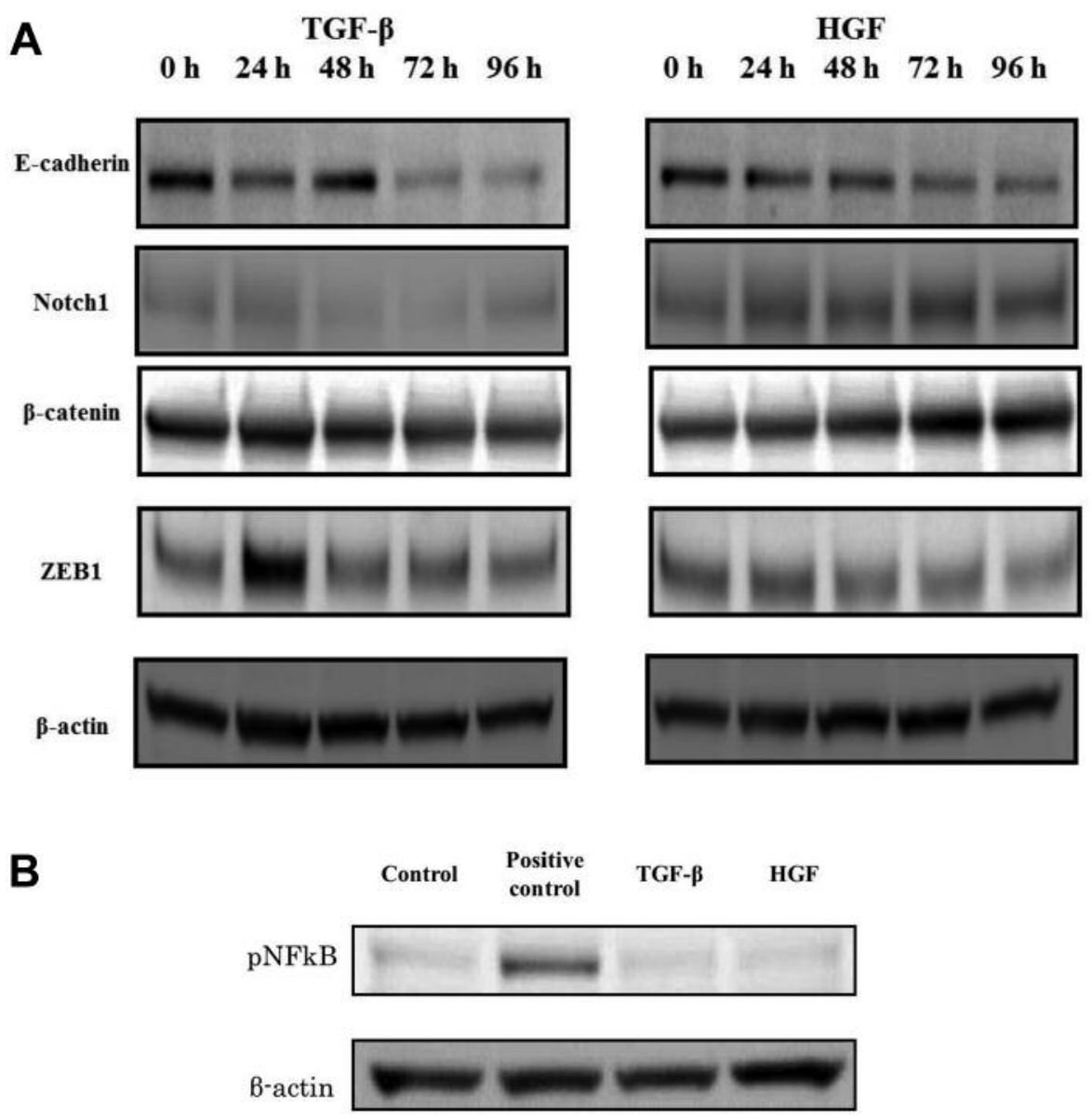

Figure 3. EMT signaling pathway. Both TGF- $\beta$ and HGF decreased the expression of E-cadherin, and TGF- $\beta$ induced the activation of ZEB1/Notch1 and decreased the expression of $\beta$-catenin in a time-dependent manner, but the activation of these pathways was not detected by HGF (A). A factor of anti-cancer drug resistance, $N F k B$ was not activated by either TGF- $\beta$ or HGF, despite both being detected by a positive factor, tumor necrosis factor- $\alpha(B)$.

performed (Figure 5). The expression of E2F1 was decreased significantly to $50.5 \pm 3.8 \%$ after $24 \mathrm{~h}$ by $\mathrm{HGF}$ with a reduction of both cyclin D1 and $\mathrm{E}$ to $52.1 \pm 7.0 \%$ and $73.7 \pm 3.8 \%$, respectively. Thymidylate synthase (TS) was also decreased in a time-dependent manner to $80.6 \pm 2.0 \%$ and $52.7 \pm 1.5 \%$ for 24 and $96 \mathrm{~h}$, respectively.

\section{Discussion}

EMT is demonstrated as a loss of epithelial markers, such as E-cadherin or a gain of mesenchymal markers, such as the vimentin and the ZEB family of proteins (14). TGF- $\beta$ is essential for the induction of EMT during various stages of embryogenesis and is important in the progression of carcinoma to an invasive state. As well, Notch, the surface receptor related to $\mathrm{TGF} / \mathrm{Smad}$, is important not only in the mediation of EMT (15), but also the survival of cancer cells
(16). In the present study, the expression of E-cadherin was decreased with the activation of Notch 1 and ZEB1 by TGF- $\beta$. In contrast, HGF was found to reduce E-cadherin but showed no effects on either Notch 1 or ZEB1. In fact, because substantial activation of the HGF/c-Met pathway leads to scattering of cancer cells (17), the suggestion that HGF regulates EMT might be possible. In the process of hepatocyte to hepatoma, HGF leads to the decreased expression of E-cadherin and an increase in vimentin through not only common EMT pathway but also some other signaling factors (10). In our previous report on the same cell line (1), during the activation of the HGF/c-Met pathway, mitogen-activated protein kinase or phosphoinositide 3-kinase was shown to act as a key point to induce EMT independently from main EMT pathway, and this was supported by recent reports $(18,19)$. The process of EMT is also important in conferring drug resistance to several cancer 


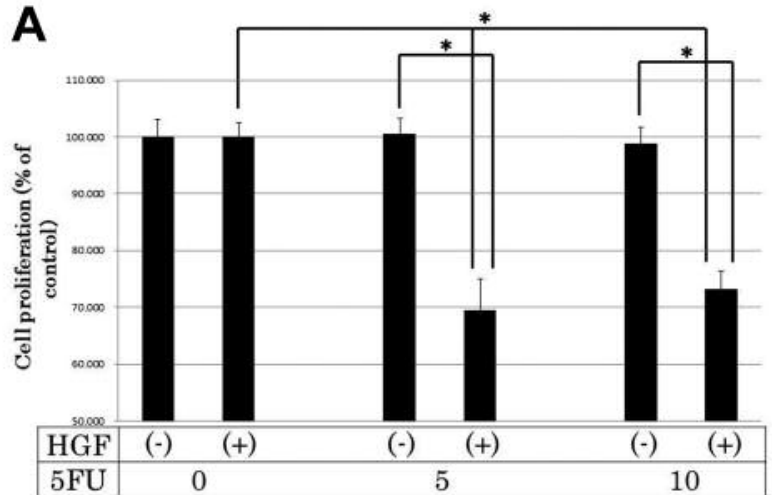

B

\begin{tabular}{|c|c|c|c|c|}
\hline $\begin{array}{c}\text { HGF } \\
20 \mathrm{ng} / \mathrm{ml}\end{array}$ & $(-)$ & $(+)$ & $(-)$ & $(+)$ \\
\hline $\begin{array}{c}5 \mathrm{FU} \\
50 \mu \mathrm{M}\end{array}$ & $(-)$ & $(-)$ & $(+)$ & $(+)$ \\
\hline \multicolumn{5}{|l|}{$0 \mathrm{~h}$} \\
\hline \multicolumn{5}{|l|}{$72 \mathrm{~h}$} \\
\hline $96 \mathrm{~h}$ & & & 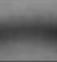 & \\
\hline$\beta$-actin & & & & \\
\hline
\end{tabular}

Figure 4. The effect of HGF for 5-FU-induced growth inhibition. The presence of HGF increased 5-FU-induced growth inhibition by MTT assay (A). 5-FU-induced JNK activation was clearly increased by pretreatment with HGF for 72 or $96 h(B)$. Each band was evaluated by computer software and the percentage of the comparison with each band of $\beta$-actin was calculated.

cells against conventional therapeutics including oxaliplatin (20). NF-kB is regulated with drug resistance-related gene expression in cancer cells, and its inhibition increases drugsensitivity for chemotherapy, indicating that NF-kB itself acts as one of the drug-resistant factors. In fact, NF-kB activation was recently implicated in EMT, and reversal of EMT was triggered by NF-kB inhibition (21). However, in the present study, NF-kB was not activated by either TGF- $\beta$ or HGF, indicating that the drug-resistant manner of EMT was not related in this cell line. These differences in signaling pathways mediating the effect of chemotherapeutic agents are not yet clear, but there is a possibility of the NF-kBindependent appearance of EMT (22).

5-FU, which has held a central position in chemotherapy for several solid types of cancer, is a critical factor in the recently developed FOLFOX or FOLFILI regimens. It is the
A

$0 \mathrm{~h}$

$24 \mathrm{~h}$

Cyclin D

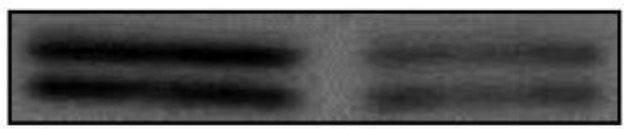

Cyclin E

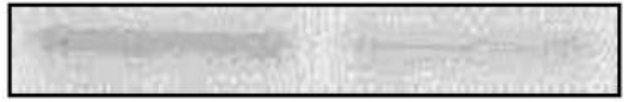

E2F1

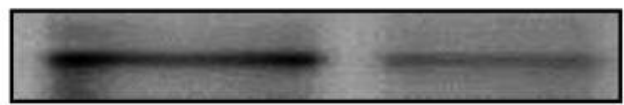

$\beta$-catenin

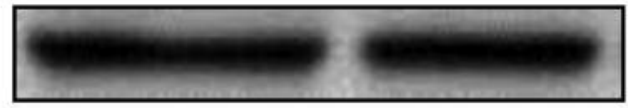

B

$0 \mathrm{~h}$

$24 \mathrm{~h}$

$48 \mathrm{~h}$

$72 \mathrm{~h}$

$96 \mathrm{~h}$

TS

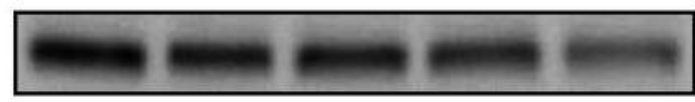

$\beta$-actin

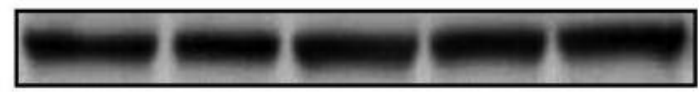

Figure 5. The mechanism of the increased effect of 5-FU induced by $H G F$. The expression of E2F1 was decreased at $24 \mathrm{~h}$ after addition of $H G F$ with reduction of cyclin D1 and E (A). Thymidylate synthase (TS) was clearly decreased after 24 hours in a time-dependent manner (B). Each band was evaluated by computer software and the percentage of the comparison with each band of $\beta$-actin was calculated. first rationally designed anti-metabolite to achieve its therapeutic efficacy through inhibition of DNA repair and its metabolism is regulated mainly by enzymes such as TS (23). CRC patients with low levels of TS were reported to have better prognosis than those with high levels (24), and gene amplification of TS with consequent increases in mRNA and protein expression was observed in a 5-FU-resistant cell line (25). Taken together, the expression of TS appears to be a more useful indicator for the prediction of chemosensitivity. As the transcriptional factor of $\mathrm{TS}, \mathrm{E} 2 \mathrm{~F}$ reverses to an activated style, by splitting of the complex with phosphoretinoblastoma $(\mathrm{Rb})$ protein, and regulates TS expression (26). The D-type cyclins play a critical role in the early $G_{1}$ phase of the cell cycle and the complex with its relatedfactors phosphorylate the $\mathrm{Rb}$ protein and inactivate its ability to act as a transcriptional repressor in a complex with E2F. 
The release of E2F leads to transcriptional induction of genes required for progression from the $G_{1}$ to $S$ phase, most notably cyclin E. Therefore, down-regulation of cyclin D1 mediates the shutdown of E2F-mediated transcriptional activity (27). This leads to the dissociation of the $\mathrm{pRb} / \mathrm{E} 2 \mathrm{~F}$ complex and the subsequent release of the transcriptional activity of E2Fs (28). The present study showed that pretreatment with HGF induced the EMT-mediated higher sensitivity of 5-FU, and these results were supported by the TS/E2F theory with the cell cycle. Among the MAPKs to transmit extracellular signals to regulate cell proliferation, apoptosis and autophagy, JNK is commonly known as a response to antitumor agents or death signals (29). In addition, 5-FU-induced JNK activation is critical to the initiation of cancer cell apoptosis. Then, the increased expression of 5-FU-induced JNK by HGF will induce HGFmediated EMT to increase the sensitivity to 5-FU.

In conclusion, the presence of HGF was found to increase the 5-FU-induced death signal because the decrease of E2F-1 by HGF inactivated TS. A previous study revealed that the best procedure for favorable patient prognosis was to plan a hepatectomy after administration of FOLFOX for 12 weeks and rest for 4 weeks $(7,30)$. The present study may lead to a novel concept in which a hepatectomy-induced high serum level of HGF for liver regeneration allows drug-resistant cancer cells to become sensitive again through the process of EMT.

\section{References}

1 Tanahashi T, Osada S, Yamada A, Kato J, Yawata K, Mori R, Imai H, Sasaki Y, Saito S, Tanaka Y, Nonaka K and Yoshida K: Extracellular signal-regulated kinase and Akt activation play a critical role in the process of hepatocyte growth factor-induced epithelial-mesenchymal transition. Int J Oncol 42: 556-564, 2013.

2 Koh SL, Ager EI and Costa PL: Blockade of the reninangiotensin system inhibits growth of colorectal cancer liver metastases in the regenerating liver. Clin Exp Metastasis 31: 395-405, 2014

3 Grothey A, Sargent D and Goldberg RM: Survival of patients with advanced colorectal cancer improves with the availability of fluorouracil-leucovorin, irinotecan, and oxaliplatin in the course of treatment. J Clin Oncol 22: 1209-1214, 2004.

4 Elliott VA, Rychahou P, Zaytseva YY and Evers BM: Activation of c-Met and upregulation of CD44 expression are associated with the metastatic phenotype in the colorectal cancer liver metastasis model. PLoS One 9: e97432, 2014.

5 Osada S, Imai H, Sasaki Y, Tanaka Y, Okumura N, Nonaka, K, Takahashi T, Yamaguchi K and Yoshida K: Surgical indications for multiple and synchronous liver metastases from colorectal cancer. Hepatogastroenterology 61: 722-726, 2014

6 Viganò L, Capussotti L, Lapointe R, Barroso E, Hubert C, Giuliante F, Ijzemans JN, Miza DF, Elias D and Adam R: Early recurrence after liver resection for colorectal metastases: risk factors, prognosis, and treatment. A LiverMetSurvey-based study of 6,025 patients. Ann Surg Oncol 21: 1276-1286, 2014.
7 Sasaki Y, Osada S, Mori R, Imai H, Tanaka Y, Matsuhashi N, Okumuara N, Nonaka $\mathrm{K}$, Takahashi $\mathrm{T}$ and Yoshida $\mathrm{K}$ : Determining timing of hepatectomy for colorectal cancer with distant metastasis according to imaging-based tumor shrinkage ratio. Int J Med Sci 10: 1231-1241, 2013.

8 Jahn SC, Law ME, Corsino PE, Parker NN, Pham K, Davis BJ, $\mathrm{Lu} \mathrm{J}$ and Law BK: An in vivo model of epithelial to mesenchymal transition reveals a mitogenic switch. Cancer Lett 326: 183-190, 2012.

9 Cañadas I, Taus A, González I, Villiaueva X, Gimero J, Pijuan L, Domine M, Sanchez-Font A, Vollmer I, Menendez S, Arpi O, Mojal S, Rojo F, Rovira A, Albaneell J and Arriola E: High circulating hepatocyte growth factor levels associate with epithelial to mesenchymal transition and poor outcome in small cell lung cancer patients. Oncotarget 5: 5246-5256, 2014.

10 Ogunwobi $\mathrm{OO}$ and Liu C: Hepatocyte growth factor upregulation promotes carcinogenesis and epithelialmesenchymal transition in hepatocellular carcinoma via Akt and COX-2 pathways. Clin Exp Metastasis 28: 721-731, 2011.

11 Koo JS, Jung W and Jeong J: The predictive role of E-cadherin and androgen receptor on in vitro chemosensitivity in triplenegative breast cancer. Jpn J Clin Oncol 39: 560-568, 2009.

12 Nakamura T, Kato Y, Fuji H, Horiuchi T, Chiba Y and Tanaka $\mathrm{K}$ : E-cadherin-dependent intercellular adhesion enhances chemoresistance. Int J Mol Med 12: 693-700, 2003.

13 Matsui S, Osada S, Tomita H, Komori S, Mori R, Sanada Y, Takahasshi T, Yamaguchi K and Yoshida K: Clinical significance of aggressive hepatectomy for colorectal liver metastasis, evaluated from the HGF/c-Met pathway. Int J Oncol 37: 289-297, 2010.

14 Lamouille S, Xu J and Derynck R: Molecular mechanisms of epithelial-mesenchymal transition. Nat Rev Mol Cell Biol 15: 178-196, 2014.

15 Kopan R and Ilagan MX: The canonical Notch signaling pathway: unfolding the activation mechanism. Cell 137: 216233, 2009.

16 Xing F, Okuda H, Watabe M, Kobayashi M, Pai SK, Liu W, Pandey PR, Fukuda K, Hirota S, Sugai T, Wabayashi G, Koeda K, Kashiwaba M, Suzuki K, Chiba T, Endo M, Mo YY and Watanabe K: Hypoxia-induced Jagged 2 promotes breast cancer metastasis and self-renewal of cancer stem-like cells. Oncogene 30: 4075-4086, 2011.

17 Gregorini M, Bosio F, Rocca C, Corradetti V, Valsania T, Pattonieri EF, Bedino G, Collesi C, Libetta C, Frassoni F, Dal Canton A and Rampino T: Mesenchymal stromal cells reset the scatter factor system and cytokine network in experimental kidney transplantation. BMC Immunol 15: 44, 2014.

18 Dong $\mathrm{P}$, Konno Y, Watari H, Hosaka M, Noguchi $\mathrm{M}$ and Sakuragi N: The impact of microRNA-mediated PI3K/AKT signaling on epithelial-mesenchymal transition and cancer stemness in endometrial cancer. J Transl Med 12: 231, 2014.

19 Luo BH, Xiong F, Wang JP, Li JH, Zhong M, Liu QL, Yang XJ, Xiao N, Xie B, Xiao H, Liu RJ, Dong CS, Wang KS and Wen JF: Epidermal growth factor-like domain-containing protein 7 (EGFL7) enhances EGF receptor-AKT signaling, epithelialmesenchymal transition, and metastasis of gastric cancer cells. PLoS One 9: e99922, 2014.

20 Wang Z, Li Y, Ahmad A, Azmi AS, Kong D, Banerjee S and Sarkar FH: Targeting miRNAs involved in cancer stem cell and EMT regulation: An emerging concept in overcoming drug resistance. Drug Resist Updat 13: 109-118, 2010. 
21 Naugler WE and Karin M: NF-kappaB and cancer-identifying targets and mechanisms. Curr Opin Genet Dev 18: 19-26, 2008.

22 Bentires-Alj M, Barbu V, Fillet M, Chariot A, Relic B, Jacobs N, Gielen J, Merville MP and Bours V: NF-kappaB transcription factor induces drug resistance through MDR1 expression in cancer cells. Oncogene 22: 90-97, 2003.

23 Vinod BS, Antony J, Nair HH, Puliyappadamba VT, Saikia M, Narayanan SS, Bevin A and Anto RJ: Mechanistic evaluation of the signaling events regulating curcumin-mediated chemosensitization of breast cancer cells to 5-fluorouracil. Cell Death Dis 4: e505, 2014.

24 Kumamoto K, Kuwabara K, Tajima Y, Amano K, Hatano S, Ohsawa T, Okada $\mathrm{N}$, Ishibashi $\mathrm{K}$, Haga $\mathrm{N}$ and Ishida $\mathrm{H}$ : Thymidylate synthase and thymidine phosphorylase mRNA expression in primary lesions using laser capture microdissection is useful for prediction of the efficacy of FOLFOX treatment in colorectal cancer patients with liver metastasis. Oncol Lett 3: 983-989, 2014.

25 Johnston PG, Drake JC, Trepel J and Allegra CJ: Immunological quantitation of thymidylate synthase using the monoclonal antibody TS 106 in 5-fluorouracil-sensitive and -resistant human cancer cell lines. Cancer Res 52: 4306-4312, 1992.

26 Banerjee D, Gorlick R, Liefshitz A, Danenberg K, Danenberg PC, Danenberg PV, Klimsta D, Jhanwar S, Cordon-Cardo C, Fong Y, Kemeny N and Bertino JR: Levels of E2F-1 expression are higher in lung metastasis of colon cancer as compared with hepatic metastasis and correlate with levels of thymidylate synthase. Cancer Res 60: 2365-2367, 2000.
27 Kobayashi S, Shimamura T, Monti S, Steidl U, hetherington CJ, Lowell AM, Golub T, Meyerson M, Tenen DG, Shapiro GI and Halmos B: Transcriptional profiling identifies cyclin D1 as a critical downstream effector of mutant epidermal growth factor receptor signaling. Cancer Res 66: 11389-11398, 2006.

28 Leshem $\mathrm{Y}$ and Halevy O: Phosphorylation of $\mathrm{pRb}$ is required for HGF-induced muscle cell proliferation and is p27kip1dependent. J Cell Physiol 191: 173-182, 2002.

29 Sui X, Kong N, Wang X, Fang Y, Hu X, Xu Y, Chen W, Wang K, Li D, Lin W, Lou F, Zheng Y, Hu H, Gong L, Zhou X, Pan $\mathrm{H}$ and Han W: JNK confers 5-fluorouracil resistance in p53deficient and mutant p53-expressing colon cancer cells by inducing survival autophagy. Sci Rep 4: 4694, 2014.

30 Osada S, Imai H, Sasaki Y, Tanaka Y, Tokuyama Y, Okumura N, Nonaka K, Takahahi T, Yamaguchi K and Yoshida K: Strategy for synchronous and multiple liver metastasis. Hepatogastroenterology 59: 198-203, 2012.
Received November 14, 2017

Revised November 28, 2017

Accepted November 29, 2017 